\title{
Climatology and trends in the forcing of the stratospheric ozone transport
}

\author{
E. Monier ${ }^{1}$ and B. C. Weare ${ }^{2}$ \\ ${ }^{1}$ Joint Program on the Science and Policy of Global Change, Massachusetts Institute of Technology, Cambridge, \\ Massachusetts, USA \\ ${ }^{2}$ Atmospheric Science Program, Department of Land, Air and Water Resources, University of California, Davis, Davis, \\ California, USA
}

Received: 29 November 2010 - Published in Atmos. Chem. Phys. Discuss.: 1 February 2011

Revised: 1 June 2011 - Accepted: 20 June 2011 - Published: 4 July 2011

\begin{abstract}
A thorough analysis of the ozone transport was carried out using the Transformed-Mean Eulerian (TEM) tracer continuity equation and the European Centre for Medium-Range Weather Forecasts (ECMWF) Re-Analysis (ERA-40). In this budget analysis, the chemical net production term, which is calculated as the residual of the other terms, displays the correct features of a chemical sink and source term, including location and seasonality, and shows good agreement in magnitude compared to other methods of calculating ozone loss rates. This study provides further insight into the role of the eddy ozone transport and underlines its fundamental role in the recovery of the ozone hole during spring. The trend analysis reveals that the ozone hole intensification over the 1980-2001 period is not solely related to the trend in chemical losses, but more specifically to the balance between the trends in chemical losses and ozone transport. That is because, in the Southern Hemisphere from October to December, the large increase in the chemical destruction of ozone is balanced by an equally large trend in the eddy transport, associated with a small increase in the mean transport. This study shows that the increase in the eddy transport is characterized by more poleward ozone eddy flux by transient waves in the midlatitudes and by stationary waves in the polar region. Overall, this study makes clearer the close interaction between the trends in ozone chemistry and ozone transport. It reveals that the eddy ozone transport and its long-term changes are an important natural mitigation mechanism for the ozone hole. This work also underlines the need for diagnostics of the eddy transport in chemical transport models used to investigate future ozone recovery.
\end{abstract}

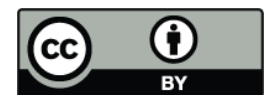

Correspondence to: E. Monier (emonier@mit.edu)

\section{Introduction}

In the 1920s, chlorofluorocarbons (CFC) started replacing more toxic compounds like ammonia, chloromethane or sulfur dioxide as refrigerants as well as propellants in aerosol cans, fire extinguishers or cleaning solvents. In 1974, CFCs were identified as the major source of ozone-destroying stratospheric chlorine (Molina and Rowland, 1974), a chemical element that was shown could engage in a catalytic cycle resulting in ozone destruction (Stolarski and Cicerone, 1974). Since then, countless observational studies have reported that the total column ozone has decreased over many regions of the globe since about 1980, with particularly severe ozone depletion over the Antarctica in the spring, leading to what is now referred to as the ozone hole. Over Antarctica, extreme low temperatures during winter and early spring facilitate the formation of polar stratospheric clouds (PSCs), which support chemical reactions that produce active chlorine, which goes on to catalyze ozone destruction. The adoption of the Montreal Protocol 1987, banning the production of CFCs and other ozone depleting chemicals, has made the ozone hole a scientific success story and was called the most successful international environmental agreement.

However, Molina and Rowland (1974) and Rowland and Molina (1975) pointed out that CFCs have very long atmospheric residence times and they would continue to deplete the stratospheric ozone well into the twenty-first century. While there has been clear evidence of a recovery since the late 1990s, this fact was well illustrated by recent observations of the 2006 ozone hole, the largest to date. As a result, the study of the ozone depletion is still drawing a large interest, especially since scientists are starting to acknowledge the impact of climate change on the stratosphere. In the recent past, many observational and modeling studies have focused

Published by Copernicus Publications on behalf of the European Geosciences Union. 
on ozone variability and trend (Brunner et al., 2006; Garcia et al., 2007; Randel and Wu, 2007; Fischer et al., 2008; Jiang et al., 2008a,b). They all take advantage of the increasing high quality and diversity of models and observational datasets. The onset of comprehensive ozone and meteorological re-analysis allowed for a better analysis of the dynamics of the ozone transport in the stratosphere. While Sabutis (1997) restricted his analysis of the mean and eddy transport of ozone to the period 15 January 1979 to 10 February 1979, many subsequent studies of the dynamics of the stratospheric ozone transport were extended to larger datasets (Cordero and Kawa, 2001; Gabriel and Schmitz, 2003; Miyazaki and Iwasaki, 2005; Miyazaki et al., 2005). A large effort has also been devoted to the estimation of chemical ozone loss rates from observations using various techniques such as the Match technique (Becker et al., 1998; Sasano et al., 2000), ozone-tracer correlations (Richard et al., 2001), Lagrangian transport models (Manney et al., 2003) or chemical transport model passive substraction (Feng et al., 2005a,b; Singleton et al., 2005, 2007). However, there is still a great deal of uncertainty in the accurate measurement of ozone chemical rate loss over large periods of time. Other areas of research include modeling studies to investigate the impact of climate change on ozone (Jiang et al., 2007). The recovery of ozone during the 21st century (Oman et al., 2010; Eyring et al., 2010) points out the need to separate dynamical and chemical contributions to long-term ozone changes in order to evaluate the influences of changing CFC amounts and the impacts of climate change. Other more theoretical studies involve examining the impact of the wave- and zonal meanozone feedback on the stratospheric dynamics, including the quasi-biennial oscillation (QBO) (Cordero et al., 1998; Cordero and Nathan, 2000) and the vertical propagation of planetary waves (Nathan and Cordero, 2007). Overall, there seems to be a lack of thorough analysis of the impact of wave-induced transport on the long-term changes in stratospheric ozone based on meteorologically consistent threedimensional ozone datasets.

Thus the aim of this study is to investigate the role of the various dynamical forcings on the transport of zonal-mean ozone and its long-term changes, using a thorough budget analysis of the Transformed-Mean Eulerian (TEM) formulation of the tracer continuity equation with the European Centre for Medium-Range Weather Forecasts (ECMWF) ReAnalysis (ERA-40). The TEM formulation offers a useful diagnostic to interpret the forcing of the ozone transport by eddies (Andrews et al., 1983). This work intends on providing a more comprehensive understanding of the contribution of planetary waves, their stationary and transient components, to the transport of ozone. Such analysis is vital as the impact of long-term changes in ozone and wave activity on the dynamics of the stratosphere is not yet fully understood.

\section{Data and methodology}

\subsection{Data}

In this study we use the six-hourly ERA-40 re-analysis (Uppala et al., 2005) in order to calculate the various terms involved in the Transformed Eulerian-Mean formulation of the ozone transport equation. These terms include flux quantities like the eddy flux vector and the residual mean meridional circulation. The ERA-40 was chosen because it provides a complete set of meteorological and ozone data, over the whole globe on a $2.5^{\circ} \times 2.5^{\circ}$ grid and over a long time period (1957-2001). The ERA-40 compares well with independent ground-based Dobson observations, Microwave Limb Sounder (MLS) satellite and ozonesonde data, both in total ozone and in ozone profiles (Dethof and Hólm, 2004). The ERA-40 ozone field has also been compared with Upper Atmosphere Research Satellite (UARS) and Measurements of Ozone and Water Vapour by Airbus In-Service Aircraft (MOZAIC) measurements, showing broad agreement (Oikonomou and O'Neill, 2006). The ERA-40 shows several weaknesses, such as an enhanced Brewer-Dobson (B-D) circulation (van Noije et al., 2004; Uppala et al., 2005) and a weaker Antarctic ozone hole of less vertical extent than the independent observations (Oikonomou and O'Neill, 2006). There is also the presence of vertically oscillating stratospheric temperature biases over the Arctic since 1998 and over the Antarctic during the whole period (Randel et al., 2004). In addition, the pre-satellite ERA-40 data in the Southern Hemisphere (SH) stratosphere are unrealistic (Renwick, 2004; Karpetchko et al., 2005). Nonetheless, the ERA40 re-analysis provides a reasonable ozone and meteorological dataset in the lower stratosphere during the satellite era. For this reason, the climatological analysis of the wave forcing of the stratospheric ozone transport is performed over the 1980 to 2001 period and for pressure levels up to $10 \mathrm{hPa}$.

\subsection{Methodology}

\subsubsection{Transformed Eulerian-Mean formulation}

This study uses the Transformed Eulerian-Mean (TEM) formulation of the zonal-mean tracer continuity equation in log-pressure and spherical coordinates in order to accurately diagnose the eddy forcing of the zonal-mean transport of stratospheric ozone. In spherical geometry, the TEM zonal-mean ozone tracer continuity equation is (based on Eq. 3.72 from Brasseur and Solomon, 2005 and on Garcia and Solomon, 1983): 


$$
\begin{aligned}
\underbrace{\frac{\partial \bar{\chi}}{\partial t}}_{\text {Ozone tendency }}= & \underbrace{-\frac{\bar{v}^{\star}}{R} \frac{\partial \bar{\chi}}{\partial \phi}-\bar{w}^{\star} \frac{\partial \bar{\chi}}{\partial z}}_{\text {Mean ozone transport }} \\
& \underbrace{-\frac{1}{\rho_{0}} \nabla \cdot \boldsymbol{M}}_{\text {Eddy ozone transport Chemical term }}+\underbrace{\bar{S}}_{\text {Chom }}
\end{aligned}
$$

In Eq. (1) and in the following equations, $\chi$ is the ozone volume mixing ratio and $\bar{v}^{\star}, \bar{w}^{\star}$ are, respectively, the horizontal and vertical components of the residual mean meridional circulation defined by (Eqs. 3.5.1a and 3.5.1b from Andrews et al., 1987):

$\bar{v}^{\star}=\bar{v}-\frac{1}{\rho_{0}} \frac{\partial}{\partial z}\left(\rho_{0} \frac{\overline{v^{\prime} \theta^{\prime}}}{\bar{\theta}_{z}}\right)$

$\bar{w}^{\star}=\bar{w}+\frac{1}{a \cos \phi} \frac{\partial}{\partial \phi}\left(\cos \phi \frac{\overline{v^{\prime} \theta^{\prime}}}{\bar{\theta}_{z}}\right)$

where the overbars and primes indicate respectively the zonal means and departures from the zonal mean. $\theta$ is the potential temperature, $v$ is the meridional wind and $w$ is the vertical wind. $\nabla \cdot \boldsymbol{M}$ is the divergence of the eddy flux vector and represents the eddy transport of ozone. The components of the eddy flux vector $\boldsymbol{M}$ are defined by (based on Garcia and Solomon, 1983):

$$
\begin{aligned}
& \boldsymbol{M}^{(\phi)}=\rho_{0}\left(\overline{v^{\prime} \chi^{\prime}}-\frac{\overline{v^{\prime} \theta^{\prime}}}{\bar{\theta}_{z}} \frac{\partial \bar{\chi}}{\partial z}\right) \\
& \boldsymbol{M}^{(z)}=\rho_{0}\left(\overline{w^{\prime} \chi^{\prime}}+\frac{1}{a} \frac{\overline{v^{\prime} \theta^{\prime}}}{\bar{\theta}_{z}} \frac{\partial \bar{\chi}}{\partial \phi}\right)
\end{aligned}
$$

Following that sign convention, the eddy flux vector represents the mass flux of ozone eddies by the wave components of the wind velocities. Finally, $\bar{S}$ is the chemical net production term, which is calculated as the residual of the other terms.

Dunkerton (1978) showed that the B-D circulation should be interpreted as a Lagrangian mean circulation and could be approximated by the residual mean meridional circulation of the TEM equations. Thus the various processes influencing the evolution of the zonal-mean ozone that are investigated in this study are separated into three categories: the advection of ozone by the B-D circulation or mean ozone transport, the large-scale eddy transport, diagnosed by the divergence of the eddy flux vector, and the chemical net production term. The signs shown in Eq. (1) are included in the various displayed terms. Each term is calculated using the six-hourly ERA-40 dataset. In addition, this formulation only allows for the calculation of the resolved eddies (dominated by planetary waves) and we do not attempt to parameterize the eddy flux divergence due to small-scale disturbances, such as gravity waves, using diffusion coefficients as described in Garcia and Solomon (1983) due to a lack of observations to evaluate such coefficients. Therefore, any contribution from the gravity waves to the eddy flux divergence would be included in the residual term. For this reason, the residual term can only be an approximation of the net chemical production term. Finally, all derivatives are computed using centered finite differences.

\subsubsection{Stationary and transient components}

Because both mean and eddy ozone transport are primarily driven by planetary waves, whether directly or indirectly, it is useful to decompose the ozone transport forcing into contributions from stationary and transient waves. Stationary planetary waves are excited by the orography (Charney and Eliassen, 1949), especially in the $\mathrm{NH}$, as well as by landsea heating contrasts, which vary on the seasonal time scale. Planetary transient waves, on the other hand, have smaller time scales ranging from a few days to a couple weeks and dominate synoptic weather patterns. The stationary components are computed by averaging temperature, wind and ozone fields over a month and then calculating the various terms of the TEM formulation. Once the stationary component is removed from the total term, which is calculated every six hours, only the contribution from the transient waves is left (Madden and Labitzke, 1981).

\section{Climatology of the stratospheric zonal-mean ozone transport}

\subsection{Seasonal cycle of the ozone transport budget}

Using Eq. (1), we can separate the changes in ozone into contributions from the mean transport, the eddy transport and the chemical net production. Figure 1 shows the seasonal cycle of the zonal-mean ozone tendency, its forcing terms and the ozone mixing ratio averaged between 100 and $20 \mathrm{hPa}$ (the layer where the largest concentrations of stratospheric ozone are found). The zonal-mean ozone mixing ratio has its largest values in the Northern Hemisphere high latitudes during spring with a minimum in late summer and early fall. The lowest quantities of ozone are found in the Southern Hemisphere polar region during the austral late summer and early spring and are associated with the ozone hole. The ozone tendency shows that the largest changes in ozone occur in the polar regions. In the Northern Hemisphere, there is a clear seasonal cycle in the ozone tendency with a distinct increase in ozone at high latitudes during the fall and winter and a decrease in the spring and early summer. The ozone tendency shows the complex development and decay of the SH ozone hole with a rapid decrease in July, August and September. This is followed by a strong increase in October and November and a weaker decrease in December and January. 

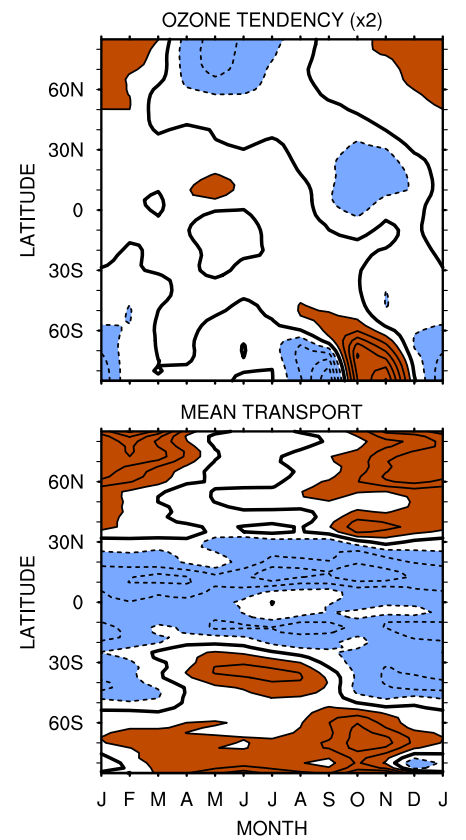

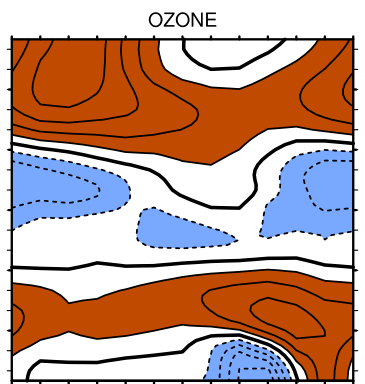

EDDY TRANSPORT

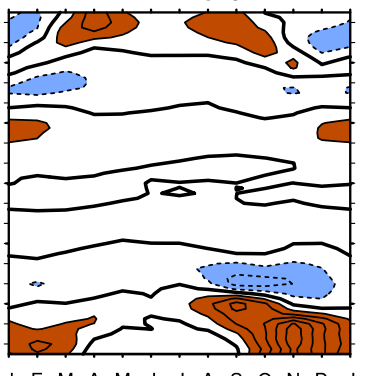

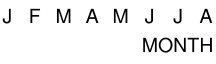

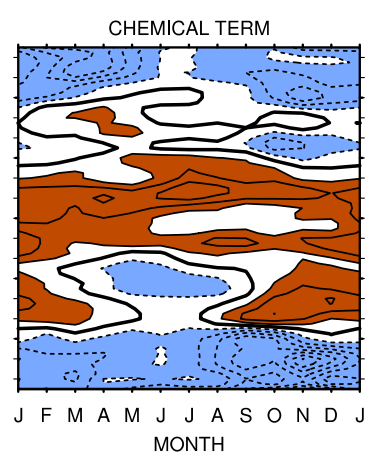

Fig. 1. Annual cycle of the zonal-mean ozone, represented by the departures from the annual global mean over the $22-\mathrm{yr}$ period ( 2 ppmv), and of the zonal-mean ozone tendency and its forcing terms, averaged between 100 and $20 \mathrm{hPa}$. Dashed (solid) lines and blue (brown) colors represent negative (positive) values; the bold solid line represents the zero-line. Contour spacing is 0.2 ppmv for the ozone and 10 ppbvday ${ }^{-1}$ for the ozone tendency and its forcing terms. Note that the ozone tendency is weak compared to its forcing terms and is therefore multiplied by 2 .

The mean transport of ozone is characterized by a net decrease in ozone in the tropics that is relatively uniform in time. In the polar regions, the mean transport generally results in a net increase in ozone, thus indicating the direct poleward transport of the B-D circulation. However, the ozone mean transport is very different between the two hemispheres. At high latitudes, the mean transport presents a pronounced seasonal cycle in the $\mathrm{NH}$ but it is weaker in the $\mathrm{SH}$ over the whole year, except for a peak in October and November. In the NH summer, the ozone mean transport is small in the midlatitudes and polar region because the B-D circulation is at its weakest (Monier and Weare, 2011). In the $\mathrm{SH}$, the ozone mean transport is weak during the austral winter because ozone cannot be advected across the stratospheric polar night jet, which is much stronger than in the NH. In the spring, the intense planetary wave activity drives a strong B$\mathrm{D}$ circulation and induces the breakdown of the polar vortex. This enables the advection of ozone-rich air from the lower latitudes into the polar region, resulting in a maximum in the mean transport. However, this is short-lived as the B-D circulation becomes weaker and reaches a minimum in January (Monier and Weare, 2011).

The eddy transport term is largely negligible in the tropics and contributes to the ozone transport budget only in the midlatitudes and polar region during specific times of the year. In the SH polar region, the ozone eddy mixing is positive during spring and winter, with a maximum in November, which is the month of strongest positive ozone tendency. This corresponds to the timing of the largest meridional gradient of ozone, south of $60^{\circ} \mathrm{S}$, and of the polar vortex breakdown, when wave breaking activity is the largest and the zonal wind is not too strong. The wave activity excites mixing between ozone-poor air near the pole and ozone-rich air from the midlatitudes, resulting in an increase in ozone in the polar region. Thus, the strength of the eddy transport is strongly dependent on wave activity, the strength of the polar vortex and on the presence of a strong meridional ozone gradient. In the $\mathrm{NH}$, the contribution of the eddy transport is smaller, mainly because the absence of an ozone hole during the late winter and spring provides for a weak meridional gradient of ozone in the midlatitudes and polar region. As a result, the maximum in eddy ozone transport in the $\mathrm{NH}$, which occurs in April, is only half as strong as in the $\mathrm{SH}$.

Finally, the chemical term shows a net chemical production in the tropics, extending into the midlatitudes in each hemisphere during spring. The creation of ozone in the tropical stratosphere is through photodissociation of molecular oxygen by ultraviolet radiation and a subsequent reaction of the oxygen atoms with molecular oxygen in the presence of a catalyst (Brasseur and Solomon, 2005). In the polar regions, the chemical term is consistently negative. The greatest ozone destruction occurs in the springtime, with maxima in April and November in the $\mathrm{NH}$ and $\mathrm{SH}$ respectively. In the SH spring, the mean ozone chemical loss rates 

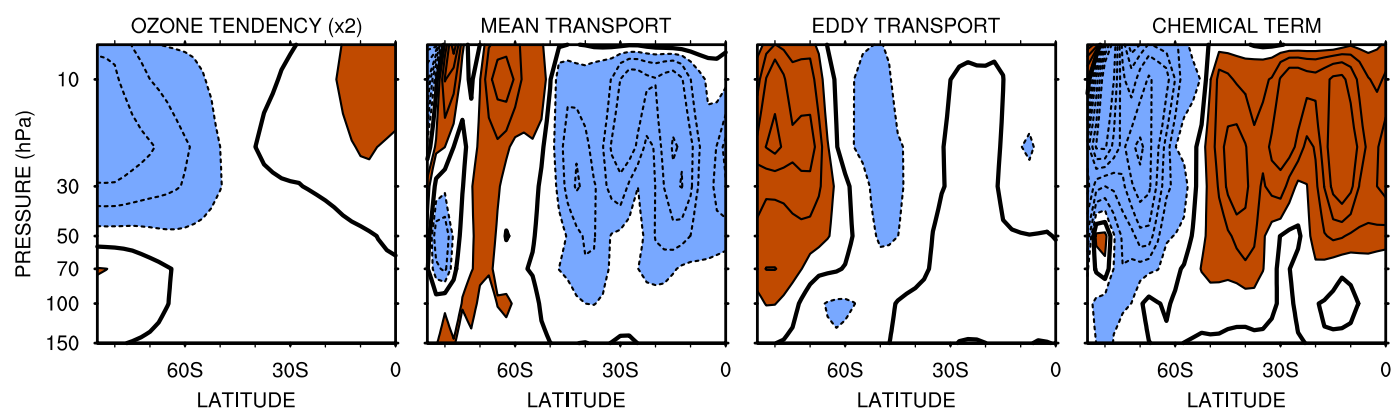

Fig. 2. Zonal-mean ozone tendency and its forcing terms averaged over DJF 1980-2001 in the SH. Dashed (solid) lines and blue (brown) colors represent negative (positive) values; the bold solid line represents the zero-line. Contour spacing is $10 \mathrm{ppbvday}^{-1}$. Note that the ozone tendency is weak compared to its forcing terms and is therefore multiplied by 2 .

of the 100-20 hPa layer can reach up to $60 \mathrm{ppbvday}^{-1}$ (or $\sim 2.5 \mathrm{DUday}^{-1}$ ). This is about one and a half time more than its counterpart in the NH spring. These results are consistent with previous studies. For example, chemical loss rates of ozone lower-stratosphere partial column $(350$ to $660 \mathrm{~K}$ or about 200 to $25 \mathrm{hPa}$ ) in the Antarctic polar region can range from 1.5 to $2.5 \mathrm{DUday}^{-1}$ in September 2000 and 2002 (Feng et al., 2005b). In the NH polar region, these rates range between 0.5 and $1.2 \mathrm{DUday}^{-1}$ for February and March 2000, 2003 and 2004 (Feng et al., 2005a). Similarly, Sasano et al. (2000) show chemical loss rates inside the Arctic polar vortex around $40 \mathrm{ppbvday}^{-1}$ from 400 to $550 \mathrm{~K}(\sim 150$ to $\sim 50 \mathrm{hPa}$ ) in March 1997 . This is consistent with the chemical loss rates inside the Arctic polar vortex of around 40 ppbvday $^{-1}$ at $450 \mathrm{~K}(\sim 100 \mathrm{hPa})$ in late February early March 2000 from Richard et al. (2001).

Overall, Fig. 1 shows that the ozone distribution results from a complex interaction between the ozone chemistry and dynamics. The ozone budget is largely driven by the balance between two large terms, the mean ozone transport and the chemical term, with the eddy transport playing mainly a secondary role except during specific times of the year. The strong poleward advection of ozone by the B-D circulation in the $\mathrm{NH}$ fall and winter is responsible for the positive ozone tendency at high latitudes. On the other hand, the weak mean ozone transport in the SH wintertime along with the chemical destruction of ozone in the polar region explains the negative ozone tendency in August and September that leads to the ozone hole. In addition, Fig. 1 shows that eddy transport is largely responsible for the positive ozone tendency in the $\mathrm{SH}$ polar region in October and November and hence contributes to the recovery of the Antarctic ozone hole in the late spring. This is consistent with the findings of Miyazaki et al. (2005) who estimate that the eddy transport represents more than $80 \%$ of the total ozone transport (advective + eddy) in the Southern Hemisphere polar region in November. In addition, November is the month where the Eliassen-Palm (EP) flux divergence shows the largest values in the region, indicating the most intense planetary wave activity and the break-down of the polar vortex (Monier and Weare, 2011). Therefore, there is a self-consistency between the seasonal variability of the EP flux divergence and the eddy flux divergence in the SH. Finally, the main characteristics of the seasonal variability of the chemical production and destruction of ozone are reproduced. Furthermore, the chemical loss rates in both the Arctic and Antarctic polar regions are in reasonable agreement with previous studies. This gives confidence in the calculation of the chemical term as a residual of the ozone transport budget. It should be noted that single year analysis can produce substantially different behavior than the 22-yr climatology presented in this study.

\subsection{Vertical structure of the ozone transport budget}

An example of the vertical structure of the various ozone forcings, for the months of December-January-February (DJF) in the SH, is shown in Fig. 2. The ozone tendency shows a distinct maximum decrease in the polar region centered at $20 \mathrm{hPa}$. The vertical structure of each forcing reveals that they are reasonably uniform with height, even though the mean transport exhibits some noise poleward of $80^{\circ} \mathrm{S}$. All the forcing terms have the largest values between the 50 and $10 \mathrm{hPa}$ levels. They also tend to show a dipole pattern with opposite effects between the polar region and the midlatitudes. The mean and eddy transports are both positive in the polar region and oppose the chemical destruction. In the subtropics, where the eddy transport and the ozone tendency are weak, the chemical net production offsets the mean transport of ozone by the B-D circulation. The chemical term shows destruction of polar ozone, with maximum values of 70 ppbvday $^{-1}$ centered at $20 \mathrm{hPa}$ and production in the tropics all the way to $50^{\circ} \mathrm{S}$, with maximum values of $40 \mathrm{ppbvday}^{-1}$ centered between 30 and $20 \mathrm{hPa}$. The distribution of the chemical term is in good agreement with the chemical transport model used in (Miyazaki and Iwasaki, 2005). Additionally, (Miyazaki and Iwasaki, 2005) find chemical loss rates for DJF of up to $7.5 \times 10^{10} \mathrm{~cm}^{-3} \mathrm{day}^{-1}$ (about $80 \mathrm{ppbvday}^{-1}$ ) centered at 

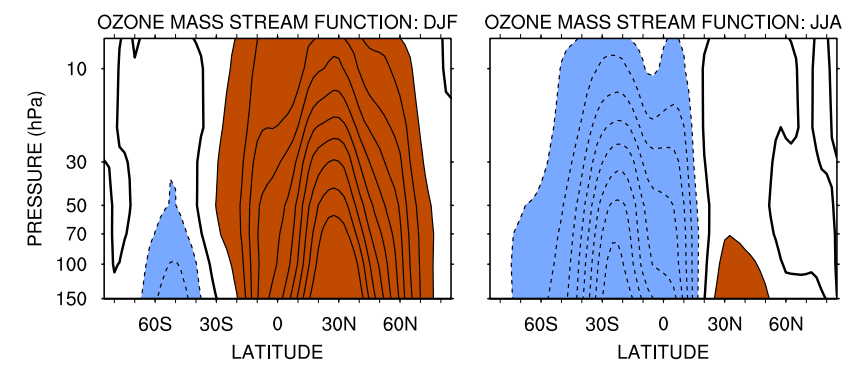

Fig. 3. Ozone density weighted Brewer-Dobson stream function averaged over (left) DJF and (right) JJA 1980-2001. Dashed (solid) lines and blue (brown) colors represent negative (positive) values; the bold solid line represents the zero-line. Contour spacing is $10^{3} \mathrm{kgs}^{-1}$.

$30 \mathrm{hPa}$ in the polar region and chemical production rates up to $3 \times 10^{10} \mathrm{~cm}^{-3} \mathrm{day}^{-1}$ (about $30 \mathrm{ppbvday}^{-1}$ ) at the same height in the tropics. Thus, there is further evidence that the distribution and the magnitude of the chemical term compare well with previous studies using chemical models, chemical transport model passive substraction and other methods based on observations.

\subsection{Mean transport}

The contributions of the horizontal and vertical transport to the mean ozone transport can be assessed from the analysis of the ozone density weighted streamfunction associated with the residual mean meridional circulation shown in Fig. 3. The ozone mass stream function shows that the mean ozone transport follows the transport description proposed by Brewer and Dobson with upward motions in the tropics and extratropical downward motions, associated with poleward motions. The ozone mass stream function presents a distinct seasonal cycle with maximum poleward transport in each hemisphere during their respective winter. This is consistent with the annual cycle of the mean ozone transport term in Fig. 1 and with other similar studies (Miyazaki and Iwasaki, 2005). It should be pointed out that there exists considerable discrepancy in the representation of the B-D circulation among the various reanalyses currently available, especially in low latitudes (Randel et al., 2008; Iwasaki et al., 2009). So while it is valid to use the ERA-40 for the demonstration of the method, the results might be influenced by the biases. This is why they should eventually be compared to results from other datasets that include meteorologically consistent three-dimensional ozone data. Nonetheless, the residual term displays the correct spatial and seasonal distribution of a chemical ozone sink and source term, and shows good agreement in magnitude compared to other methods of calculating ozone production and loss rates. This provides reasonable evidence of the validity of the ozone budget performed in this study.

\subsection{Eddy transport}

In order to better understand the origins of the eddy transport term, the horizontal and vertical eddy transport terms are evaluated along with the eddy flux vector, separated into stationary and transient components. A conspicuous feature revealed by Fig. 4 is that the eddy transport is controlled by its horizontal component as the vertical eddy transport is weak over the whole hemisphere. This can be explained by the strong influence of the eddy ozone transport on the presence of a steep meridional ozone gradient. This is consistent with the assumption that eddy transport is dominated by meridional mixing processes, which has been adopted in several studies (Tung, 1986; Newman et al., 1988; Gabriel and Schmitz, 2003). In addition the eddy transport is provided about equally by stationary and transient waves with the transient eddy transport dominating only slightly in the midlatitudes. This is consistent with the findings from Monier and Weare (2011) who look at planetary wave activity in the SH diagnosed by the Eliassen-Palm (EP) flux divergence. This analysis provides further evidence of the influence of the eddy ozone transport by the meridional ozone gradient, wave breaking activity and the strength of the polar vortex.

The components of the eddy flux vector represent the horizontal and vertical flux of ozone eddies by the wave components of the wind velocities. In comparison the eddy flux divergence corresponds to the net ozone transport in a specific region due to the net ozone eddy flux entering this region. In the SH spring the vertical eddy ozone flux is upward in the midlatitues and near the pole and downward in the subpolar region. Meanwhile, the horizontal eddy ozone flux is composed of poleward transport in the polar region and equatorward transport in the midlatitudes and subtropics. The fact that the horizontal ozone eddy flux is three orders of magnitude greater than its vertical counterpart explains its major role in the eddy transport.

The eddy ozone transport is dominated by transient processes in the midlatitudes due to high transient wave activity associated with storm tracks located near $50^{\circ} \mathrm{S}$ throughout the year (Trenberth, 1991). However, the stationary eddy transport is stronger than the transient eddy transport in the polar region. This can be explained by the presence of the asymmetric Antarctic topography and ice-sea heating contrasts driving the stationary wave activity in the polar region, as it has been demonstrated in several studies (Parish et al., 1994; Lachlan-Cope et al., 2001). This suggests that calculating the various flux terms using monthly data (i.e. considering only stationary processes) does not provide the full picture since the contribution from transient processes is considerable. Furthermore, the fact that the structure of the climatology of both transient and stationary terms can be reasonably explained (location of storm tracks and presence of topography and sea-ice heating contrasts) provides further confidence in the analysis. 

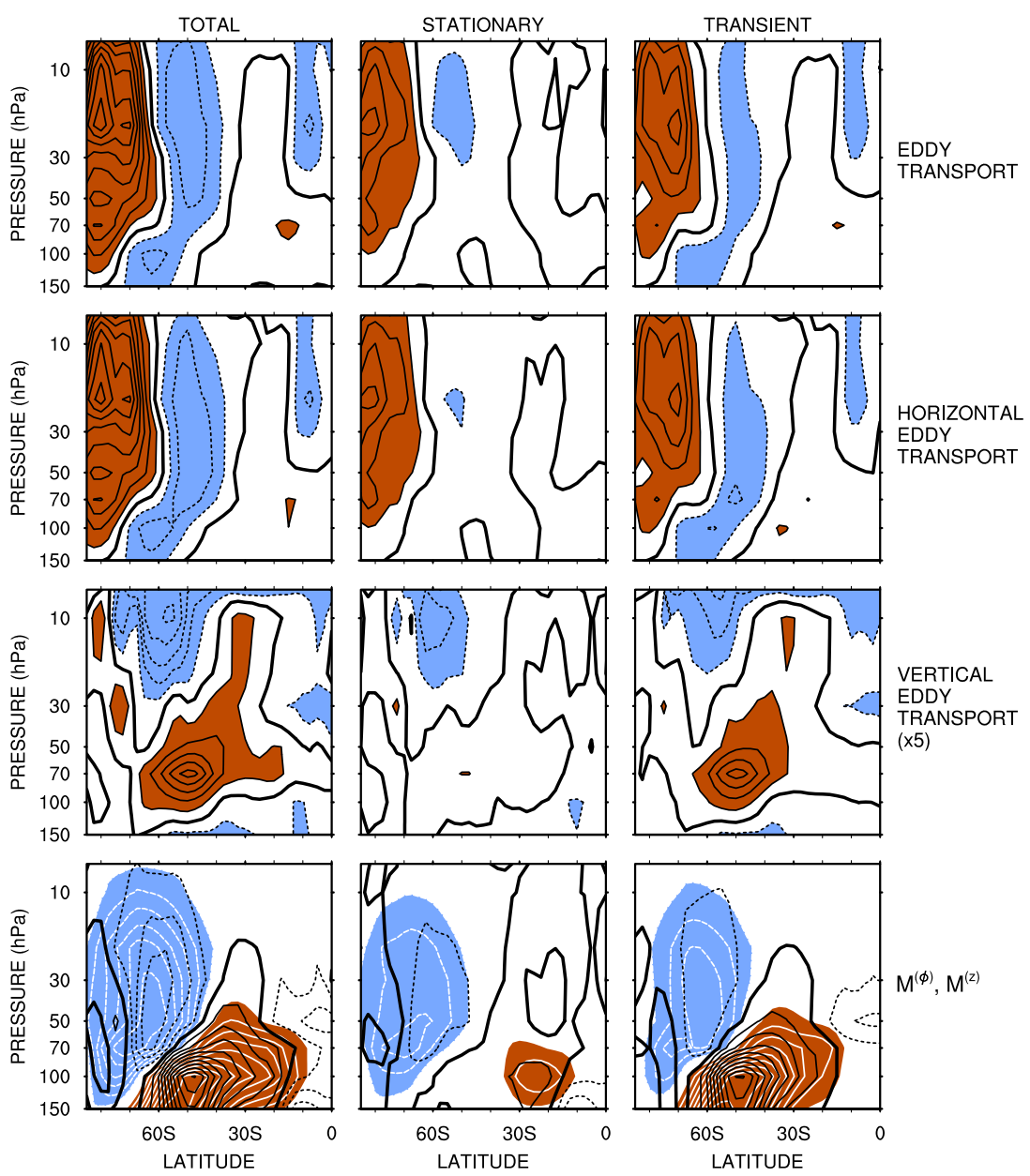

Fig. 4. Same as Fig. 2 but for the eddy ozone transport, its horizontal and vertical components, and the eddy flux vector, with the contributions of stationary and transient waves. Blue (brown) colors with dashed (solid) white lines represent negative (positive) values for $\boldsymbol{M}^{(\phi)}$. Dashed (solid) black lines represent negative (positive) values while the bold solid line represents the zero-line for $\boldsymbol{M}^{(z)}$. Contour spacing is 5 ppbvday $^{-1}$ for the eddy transport and its horizontal and vertical components, $2 \times 10^{5} \mathrm{kgppbvm}^{-2} \mathrm{day}^{-1}$ for $\boldsymbol{M}^{(\phi)}$ and $2 \times 10^{2} \mathrm{kgppbvm}^{-2} \mathrm{day}^{-1}$ for $\boldsymbol{M}^{(z)}$. Note that the vertical eddy transport is weak compared to the horizontal eddy transport and is therefore multiplied by 5 .

\section{Trends in the wave forcing of the stratospheric zonal-mean ozone transport}

\subsection{Trends in the zonal-mean ozone}

The long-term trends and interannual variability of the lower and middle stratosphere (LMS) ozone are investigated in Fig. 5. The variances and trends are calculated over the 1980-2001 period based on monthly mean ozone averaged between 100 and $20 \mathrm{hPa}$. The ozone variance, representing its interannual variability, is large in the polar region in both hemispheres during their respective late winter and early spring. A weaker variance maximum is also present in the tropics, most likely related to the Quasi-Biennial Oscillation (QBO). In the $\mathrm{SH}$, the year-to-year variability of the LMS zonal-mean ozone layer is associated with the ozone hole and located south of $60^{\circ} \mathrm{S}$. The maximum ozone trends associated with the Antarctic ozone hole occur in September at a rate above 0.5 ppmv per decade, with a $99.9 \%$ statistical significance level (calculated using a Student's t-test). There is also a negative ozone trend in the $\mathrm{NH}$ polar region during spring that corresponds to a decrease of the ozone maximum that occurs at that time. In March, the NH polar ozone has decreased between 1980 and 2001 at a rate of over 0.2 ppmv per decade, with a $93 \%$ statistical significance level. The long-term changes in the polar ozone work out to be a decrease of $\sim-10 \%$ over $22 \mathrm{yr}$ in the $\mathrm{NH}$ in March and of $\sim-40 \%$ in the SH in September. This is consistent with Brunner et al. (2006), using the Candidoz Assimilated Three-dimensional Ozone (CATO) multiple linear regression model. They find maximum negative trends north of $60^{\circ} \mathrm{N}$ in February and March at about $-5 \%$ per decade, and a maximum trend in the $\mathrm{SH}$ polar region in October, close to $-20 \%$ per decade, from 1979-2004. Moreover, the 


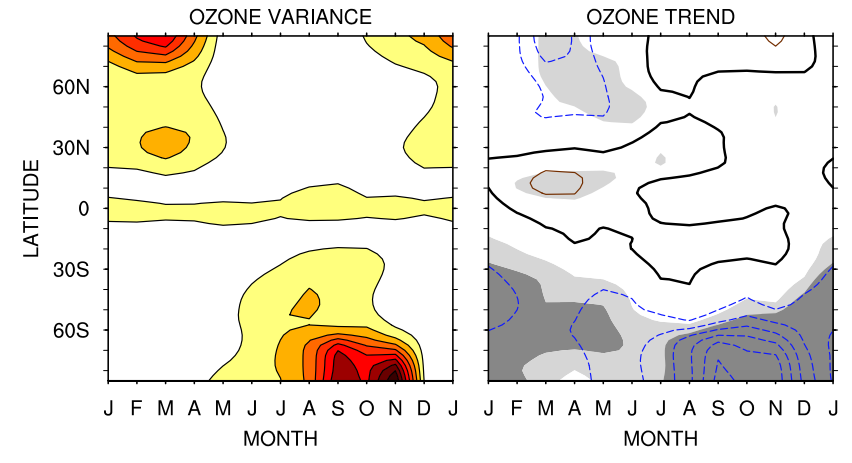

Fig. 5. Annual cycle of the ozone sample variance and trend. The variances and trends are calculated over the 1980-2001 period based on monthly mean ozone averaged between 100 and $20 \mathrm{hPa}$. Dashed blue (solid brown) lines represent negative (positive) values; the bold solid line represents the zero-line. Light grey (dark grey) shading represents the $90 \%(99 \%)$ statistical significance level of the trends. Contour spacing is $0.05 \mathrm{ppmv}^{2}$ for the ozone variance and $0.1 \mathrm{ppmv}$ per decade for the ozone trend.

seasonality of the trends is consistent with previous modeling and observational studies. Randel and Wu (2007) calculated seasonal variations of the trends in the vertically integrated ozone column derived from analysis of Stratospheric Aerosol and Gas Experiment (SAGE I and II) profile measurements, combined with polar ozonesonde data. They find a maximum trend in the polar region over the 1979 to 2005 time period in the NH April and SH October, weaker than in this study by about $10-20 \%$. This can be explained by the extended period they consider and the recovery of their equivalent effective stratospheric chlorine (EESC) proxy after 2000. Meanwhile, Garcia et al. (2007) provide a similar analysis based on the Whole-Atmosphere Community Climate Model (WACCM) column of ozone. They show maximum trends in the polar region from 1979 to 2003 in the NH February and SH October. Thus there is some uncertainty as to which month displays the maximum trends, but an overall agreement concerning the seasonality of the trends in the stratospheric polar ozone.

\subsection{Trends in the wave forcing of ozone transport}

Figure 6 shows the annual cycle of the linear trends of the ozone tendency and its forcing terms. The trends are calculated over the 1980-2001 period based on the monthly means of the various terms averaged between 100 and $20 \mathrm{hPa}$ and between $60^{\circ}-85^{\circ}$. A perhaps surprising result is that chemical destruction can take place and exhibit trends all year long. This may be explained by the work of Lamago et al. (2003), who find that when taking into account large solar zenith angles, ozone concentrations are significantly affected from June to August south of $60^{\circ} \mathrm{S}$ because of photolysis rates of $\mathrm{Cl}_{2} \mathrm{O}_{2}$. In the $\mathrm{SH}$, the largest trends occur from September to December and show that negative trends in the chemi- cal losses are largely balanced by positive trends in the eddy transport, apparently following by a month. Meanwhile, the trends in the ozone mean transport are weaker and not statistically significant (except for the month of December). The timing of the trends in the ozone chemical destruction corresponds to the ozone hole, when the polar region is the coldest due to a lack of radiative heating by ozone. When the region is very cold, PSCs can form thus inducing even more chemical destruction. Because the strength of the eddy transport is strongly dependent on not only wave breaking activity but also on the presence of a strong meridional ozone gradient, the destabilization of the ozone layer over the Antarctica leads to an increase in the spring eddy transport. As the ozone hole grows stronger year after year, so does the meridional ozone gradient. This leads to more mixing, near the edge of the polar vortex, between rich and poor regions of ozone. This explains why the trends in the eddy transport lag by one month the trends in the chemical term. It is worthy to note that the dip in the eddy flux divergence in November coincides with a weakening of the planetary wave activity, as is revealed from the trend analysis of the EP flux divergence in Monier and Weare (2011). Hence, the trends in the eddy flux divergence might be controlled not only by the variations in the meridional ozone gradient but also by the long-term changes in wave activity. The weakening of the planetary wave activity can also explain the similar dip in the ozone mean transport trends during the month of November, since the long-term weakening of the planetary wave activity is accompanied by a weakening of the B-D circulation.

In August, the strength of the polar night jet is at its maximum and it acts as an eddy mixing barrier (Haynes and Shuckburgh, 2000; Miyazaki et al., 2005). Additionally, the meridional gradient of ozone is weak at the time. As a result, the trend in the eddy ozone transport remains weak, much weaker than between September and December. Consequently, the negative trend in the chemical destruction of ozone in August, which is significantly weaker than from September to November, remains unbalanced by trends in the ozone transport. This leads to a significantly negative trend in the ozone tendency in August, which in turn is responsible for the maximum ozone trend over Antarctica that occurs in September. Thus the ozone hole intensification over 1980-2001 time period is not directly related to the trend in chemical losses, but more specifically to the balance between the trends in chemical losses and depletion influenced ozone transport.

The balance between the trends in the ozone forcing terms results in month-to-month changes in the trend in the ozone tendency. Figure 6 shows that the only statistically significant trends in the ozone tendency are negative in May, July and August (leading to the intensification of the ozone hole) and positive in October and December (leading to the intensification of the ozone hole recovery in late spring).

In the $\mathrm{NH}$, the picture is more complicated, mainly due to the absence of strong polar ozone depletion and the 

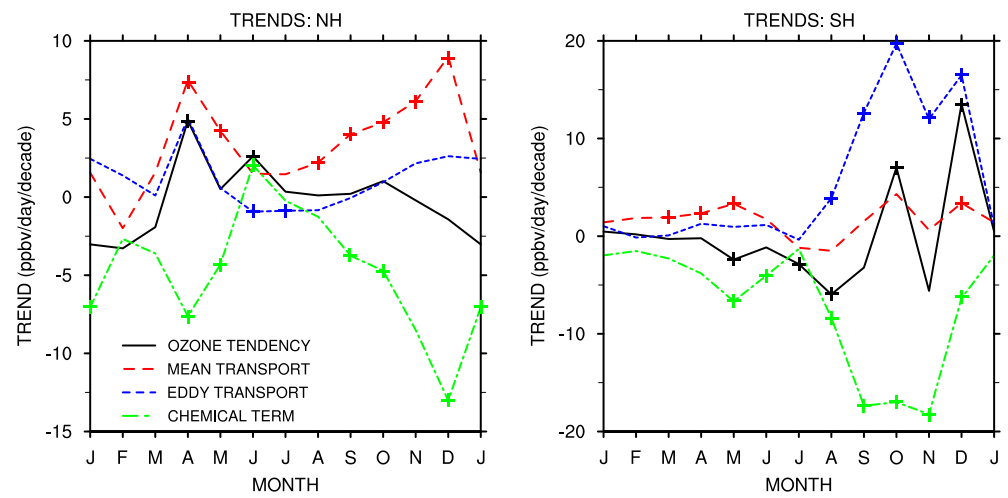

Fig. 6. Annual cycle of the trends in the ozone tendency and its forcing terms, for the (left) $\mathrm{NH}$ and the (right) SH. The trends are calculated over the 1980-2001 period based on monthly means of the various forcing terms averaged between 100 and $20 \mathrm{hPa}$ and between $60^{\circ}-85^{\circ}$. Trends that are statistically significant at the $95 \%$ statistical significance level are indicated by a cross.
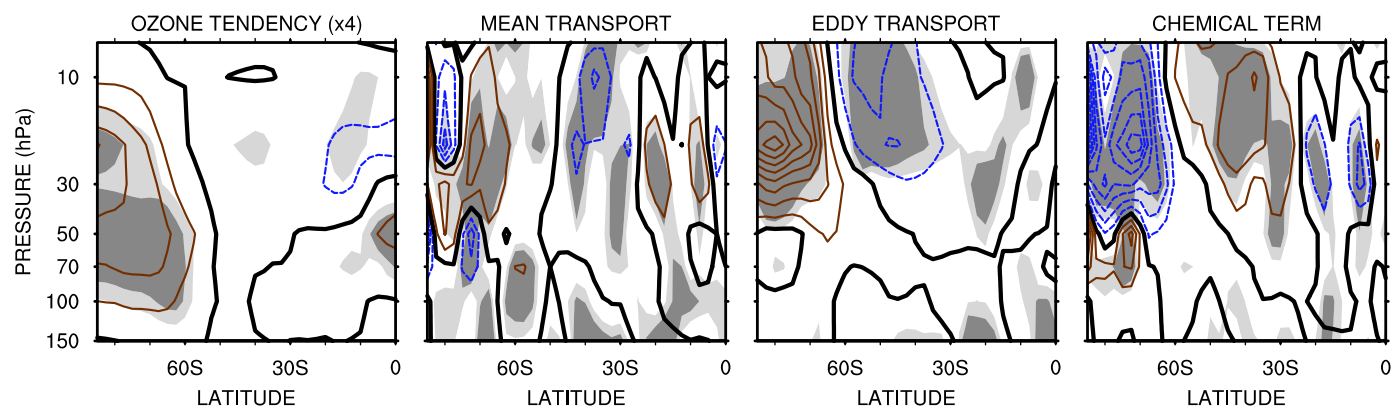

Fig. 7. OND trends in the ozone tendency and its forcing terms for the SH calculated over the 1980-2001 period. Dashed blue (solid brown) lines represent negative (positive) values; the bold solid line represents the zero-line. Light grey (dark grey) shading represents the $95 \%$ $(99 \%)$ statistical signicance level of the trends. Contour spacing is 10 ppbvday $^{-1}$ per decade. Note that the trends in the ozone tendency are weak compared to the forcings terms and are therefore multiplied by 4 .

associated meridional gradient of ozone. Overall, the negative trends in the chemical losses are balanced primarily by the positive trends in the ozone mean transport, and not the eddy transport as in the $\mathrm{SH}$, apparently at zero lag. However, the trends are much weaker than in the SH. Two particular months show distinct balances in the trends of the ozone tendency forcings. In April, increases in the mean and eddy ozone transport balance a significant increase in the ozone chemical destruction. This result is consistent with the analysis of the trends of the stratospheric wave forcing in Monier and Weare (2011) who show a delay of the polar vortex break-down and an increase in the planetary wave activity in April in the $\mathrm{NH}$, associated with an intensification of the B-D circulation. The delay in the break-down of the polar vortex can result in sustained cold temperature in April, thus extending the period of ozone chemical destruction and leading to an increase in the chemical term in April. In December, a large positive significant trend in the mean ozone transport is mirrored by a large negative significant trend in the chemical term. However, an explanation for this behavior is not clear. In the polar region, the mean ozone transport is controlled by its downward descent. Hence, the trend in the mean transport can be influenced by long-term changes in both the vertical branch of the B-D circulation and the vertical gradient of ozone. It is therefore possible that changes in the vertical profile of ozone are responsible for the large positive trend in the mean transport of ozone in December. It is also possible that the trend in the chemical loss in December in the $\mathrm{NH}$ polar region is an artifact, of either the dataset or the time period over which the trends are calculated.

Figure 7 shows latitude-height cross-sections of the trends in the ozone tendency and its forcing terms for the months of October-November-December (OND) in the SH. It illustrates the main balance between the trends in the chemical term and in the eddy transport, which applies only to this period of the year. The ozone tendency shows a significant positive trend in the polar region centered at $30 \mathrm{hPa}$, demonstrating the strengthening of the recovering ozone hole in late spring. The trends in the ozone forcing terms are noisier, particularly for the mean ozone transport, but show distinct patterns. Both mean and eddy transport present positive trends in the polar regions and negative trends at midlatitudes centered at 

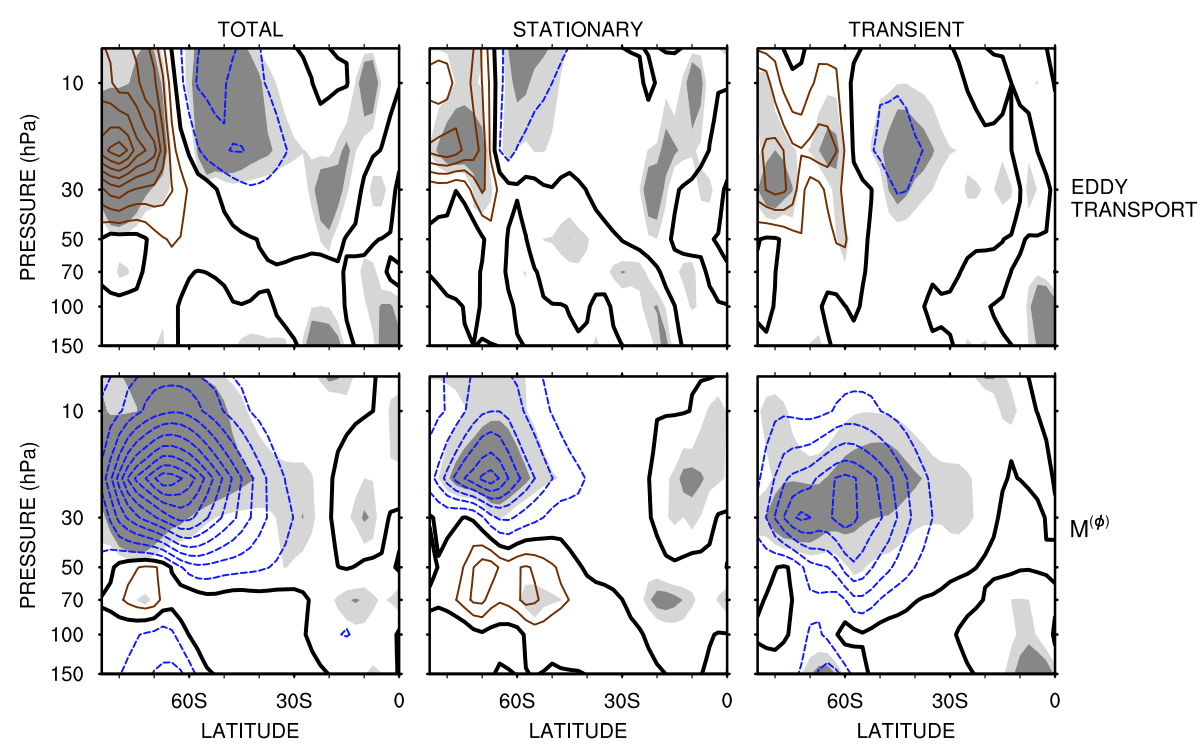

Fig. 8. Same as Fig. 7 but for the eddy ozone transport and the horizontal component of the eddy flux vector, with the contributions of stationary and transient waves. Contour spacing is $10 \mathrm{ppbvday}^{-1}$ per decade for the eddy transport and $2 \times 10^{5} \mathrm{kgppbvm}^{-2} \mathrm{day}^{-1}$ per decade for $\boldsymbol{M}^{(\phi)}$.

$20 \mathrm{hPa}$, in opposition to that of the chemical term. These trends reveal an intensification of the dipole pattern of ozone forcing shown in Fig. 2. The trends in the eddy transport are stronger than that in the mean transport, which is consistent with the results shown in Fig. 6. In the SH springtime (OND), the trends in the eddy ozone transport reach a maximum of 80 ppbvday $^{-1}$ per decade at $20 \mathrm{hPa}$ in the polar region over the 1980-2001 period. As a comparison, the mean eddy ozone transport at the same location and over the same time period is 100 ppbvday $^{-1}$. This reveals a very large increase in the eddy transport from 1980 to 2001 in the stratospheric polar region over Antarctica.

Figure 8 shows the SH latitude-height cross-sections of the OND trends in the eddy ozone transport and the horizontal component of the eddy flux vector with the contributions of stationary and transient waves. Figure 8 reveals that the trends in the eddy transport are present in both its stationary and transient components. The trend in the eddy flux vector indicates stronger poleward eddy mixing above $50 \mathrm{hPa}$ in the polar region and midlatitudes, most likely due to a stronger meridional ozone gradient caused by the ozone hole. The trend in the midlatitudes is dominated by transient wave activity, corresponding to the location of storm tracks; the contribution of stationary waves is limited to the polar region, likely associated with the presence of the asymmetric Antarctic topography and ice-sea heating contrasts. The fact that the trends are similar between the stationary and transient components of the eddy ozone transport and that their main differences (their latitudinal location) can be physically explained gives credibility to these results.

\section{Conclusions}

A thorough analysis of the ozone transport was carried out using the TEM tracer continuity equation with the ERA-40 re-analysis. The resolved terms in the ozone transport equation are the ozone tendency, the mean ozone transport by the B-D circulation and the eddy ozone transport. In addition, the residual term in the TEM ozone transport equation is shown to be representative of the chemical net production term. This is an approximation since it does also contain ozone transport due to unresolved waves, such as gravity waves. However, the chemical term displays the correct features of a chemical sink and source term, including location and seasonality, and shows good agreement in magnitude compared to other methods of calculating ozone loss rates. This provides confidence in the ozone transport budget calculated in this study. Thus, we assume that the contribution from gravity waves is negligible compared to the chemical term, which should be especially true in the polar region and tropics where chemical rates of destruction and production are large. Furthermore, the climatology of both the mean and eddy transports is consistent with previous studies (Miyazaki and Iwasaki, 2005; Miyazaki et al., 2005) using independent datasets. Consequently, the ozone budget based on the TEM tracer continuity equation presented in this study provides a reasonable method to investigate the dynamical and chemical ozone forcing over the whole globe and over long time periods using re-analysis datasets.

In the wintertime, the transport of ozone from the tropics to the polar regions is primarily controlled by the transport of ozone by the B-D circulation, which is stronger in the $\mathrm{NH}$ because the $\mathrm{SH}$ polar night jet is strong enough to 
suppress the transport of ozone across the subpolar region (Miyazaki et al., 2005). The ozone advection reaches a maximum in the late winter and early spring, when intense planetary wave activity drives a stronger B-D circulation and induces the breakdown of the polar vortex. In spring, the eddy mixing effectively transports ozone into the polar region, especially in the $\mathrm{SH}$, where the eddy transport is so large that it balances a large fraction of the chemical ozone destruction. Therefore, this study outlines the considerable contribution of eddy mixing to the overall transport of ozone in the SH. This is consistent with previous theoretical and observational studies (Muller et al., 2005; Manney et al., 2006). The chemical term shows a net production in the tropics, extending in the midlatitudes in each hemisphere during spring. In the polar regions, the chemical term is consistently negative. The greatest ozone loss occurs in the springtime, with maxima in April and November in the $\mathrm{NH}$ and $\mathrm{SH}$ respectively. This analysis clarifies the role of eddy transport in the recovery of the Antarctic ozone hole in the late spring. At the time the meridional gradient of ozone is large and the polar vortex is breaking down leading to horizontal mixing across the subpolar region between ozone-rich and ozone-poor regions. The contribution of the eddy ozone transport underlines the importance of improving climate models and their representation of wave propagation in the stratosphere, especially to investigate future ozone recovery.

The trend analysis reveals that the largest intensification of the ozone chemical destruction coincides with the timing of the Antarctic ozone hole, from September to November. However, these trends are balanced by equally large positive trends in the eddy transport, and a small increase in the mean transport. On the other hand, a weaker intensification of the ozone chemical destruction occurs in August and remains unchallenged by trends in the ozone transport. Consequently, the intensification of the ozone hole is the result of a complex balance between the trends in the chemical destruction and in the ozone transport. In August, the trend in the eddy ozone transport is weak because the strength of the polar night jet is at its maximum and it acts as an eddy mixing barrier, and because the meridional gradient of ozone remains weak. The increase in the spring eddy transport is influenced by an intensification of the meridional gradient of ozone associated with the enhancement of the ozone hole. The mixing between ozone-rich and ozone-poor regions near the edge of the polar vortex increases as a result. This is corroborated by statistically significant trends showing a tendency for stronger horizontal eddy transport from the subtropics to the pole. Transient waves are responsible for most of the trends in the midlatitudes while the contribution of stationary waves is mainly limited to the polar region. The increase in the eddy transport presents a distinct dip in November, corresponding to a decrease in planetary wave activity identified in Monier and Weare (2011). This demonstrates that the eddy transport is not only controlled by the meridional ozone gradient, but is also impacted by changes in the planetary wave activity during the polar vortex breakdown. In October and December, the increase in the eddy transport overcomes the intensification of the chemical destruction and provides the fundamental mechanism for the ozone recovery in the late spring. This study underlines the close link between the long-term changes in the ozone chemistry and transport: without an increase in the ozone chemical loss rates there would be no change in the ozone transport, and without an increase in the eddy ozone transport virtually all available ozone over Antarctica would be depleted, thus impacting the chemical loss rates. As such, the eddy ozone transport and its long-term changes are an important natural mitigation mechanism for the ozone hole.

This work suggests that care must be taken in modeling studies of future ozone recovery. If the planetary eddies (and thus the eddy ozone transport) are not simulated realistically, models can produce cold biases in the polar regions (Austin et al., 2003), leading to false statements about ozone recovery. In particular, this study shows that trends in the dynamical transport of ozone have a significant impact on the longterm changes in polar ozone. Thus it appears obvious that diagnostics of the eddy transport should be systematically carried out in chemical transport models used to investigate stratospheric ozone. Furthermore, there is a great lack of available stratospheric ozone loss rates datasets ranging over the entire globe and over a large time period, other than computed by chemical models. This study also shows that the applied methodology is a step toward filling that gap and that it should be extended and compared to other re-analysis products. Finally, a better understanding of the impact of climate change on stratospheric planetary wave activity and its potential repercussions on future ozone changes is required in light of the significant role of planetary waves on the evolution of the ozone hole.

Acknowledgements. The authors want to thank Terrence R. Nathan for his advice on this project and R. Alan Plumb for his comments, as well as the various anonymous reviewers for the helpful discussions. ERA-40 data were provided by the European Centre for Medium-Range Weather Forecasts from their website at http://data-portal.ecmwf.int/data/d/era40_daily/. This study was partially supported by the National Science Foundation grant ATM0733698.

Edited by: M. Dameris

\section{References}

Andrews, D., Holton, J., and Leovy, C.: Middle Atmosphere Dynamics, Academic Press, 489 pp., 1987.

Andrews, D. G., Mahlman, J. D., and Sinclair, R. W.: Eliassen-Palm Diagnostics of Wave-Mean Flow Interaction in the GFDL "SKYHI" General Circulation Model, J. Atmos. Sci., 40, 2768-2784, doi:10.1175/15200469(1983)040;2768:ETWATM ¿2.0.CO;2, 1983. 
Austin, J., Shindell, D., Beagley, S., Bruhl, C., Dameris, M., Manzini, E., Nagashima, T., Newman, P., Pawson, S., Pitari, G., Rozanov, E., Schnadt, C., and Shepherd, T.: Uncertainties and assessments of chemistry-climate models of the stratosphere, Atmos. Chem. Phys., 3, 1-27, doi:10.5194/acp-3-1-2003, 2003.

Becker, G., Müller, R., McKenna, D., Rex, M., and Carslaw, K.: Ozone loss rates in the Arctic stratosphere in the winter 1991/92: Model calculations compared with Match results, Geophys. Res. Lett., 25, 4325-4328, doi:10.1029/1998GL900148, 1998.

Brasseur, G. and Solomon, S.: Aeronomy of the Middle Atmosphere: Chemistry and Physics of the Stratosphere and Mesosphere, Springer, 644 pp., 2005.

Brunner, D., Staehelin, J., Maeder, J. A., Wohltmann, I., and Bodeker, G. E.: Variability and trends in total and vertically resolved stratospheric ozone based on the CATO ozone data set, Atmos. Chem. Phys., 6, 4985-5008, doi:10.5194/acp-6-49852006, 2006.

Charney, J. and Eliassen, A.: A numerical method for predicting the perturbations of the middle latitude westerlies, Tellus, 1, 38-54, doi:10.1111/j.2153-3490.1949.tb01258.x, 1949.

Cordero, E. and Kawa, S.: Ozone and tracer transport variations in the summer Northern Hemisphere stratosphere, J. Geophys. Res., 106, 12227-12239, doi:10.1029/2001JD900004, 2001.

Cordero, E. and Nathan, T.: The Influence of Wave- and Zonal Mean-Ozone Feedbacks on the Quasi-biennial Oscillation, J. Atmos. Sci., 57, 3426-3442, doi:10.1175/15200469(2000)057;3426:TIOWAZ; 2.0.CO;2, 2000.

Cordero, E., Nathan, T., and Echols, R.: An Analytical Study of Ozone Feedbacks on Kelvin and Rossby-Gravity Waves: Effects on the QBO, J. Atmos. Sci., 55, 1051-1062, doi:10.1175/15200469(1998)055;1051:AASOOF $; 2.0 . C O ; 2,1998$.

Dethof, A. and Hólm, E.: Ozone assimilation in the ERA-40 reanalysis project, Q. J. Roy. Meteorol. Soc., 130, 2851-2872, doi:10.1256/qj.03.196, 2004.

Dunkerton, T.: On the Mean Meridional Mass Motions of the Stratosphere and Mesosphere, J. Atmos. Sci., 35, 2325-2333,

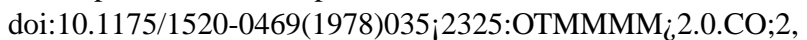
1978.

Eyring, V., Cionni, I., Bodeker, G. E., Charlton-Perez, A. J., Kinnison, D. E., Scinocca, J. F., Waugh, D. W., Akiyoshi, H., Bekki, S., Chipperfield, M. P., Dameris, M., Dhomse, S., Frith, S. M., Garny, H., Gettelman, A., Kubin, A., Langematz, U., Mancini, E., Marchand, M., Nakamura, T., Oman, L. D., Pawson, S., Pitari, G., Plummer, D. A., Rozanov, E., Shepherd, T. G., Shibata, K., Tian, W., Braesicke, P., Hardiman, S. C., Lamarque, J. F., Morgenstern, O., Pyle, J. A., Smale, D., and Yamashita, Y.: Multi-model assessment of stratospheric ozone return dates and ozone recovery in CCMVal-2 models, Atmos. Chem. Phys., 10, 9451-9472, doi:10.5194/acp-10-9451-2010, 2010.

Feng, W., Chipperfield, M., Davies, S., Sen, B., Toon, G., Blavier, J., Webster, C., Volk, C., Ulanovsky, A., Ravegnani, F., von der Gathen, P., Jost, H., Richard, E. C., and Claude, H.: Threedimensional model study of the Arctic ozone loss in 2002/2003 and comparison with 1999/2000 and 2003/2004, Atmos. Chem. Phys., 5, 139-152, doi:10.5194/acp-5-139-2005, 2005a.

Feng, W., Chipperfield, M., Roscoe, H., Remedios, J., Waterfall, A., Stiller, G., Glatthor, N., Hoepfner, M., and Wang, D.: Three-Dimensional Model Study of the Antarctic Ozone Hole in 2002 and Comparison with 2000, J. Atmos. Sci., 62, 822-837,
doi:10.1175/JAS-3335.1, 2005b.

Fischer, A. M., Schraner, M., Rozanov, E., Kenzelmann, P., Schnadt Poberaj, C., Brunner, D., Lustenberger, A., Luo, B. P., Bodeker, G. E., Egorova, T., Schmutz, W., Peter, T., and Brnnimann, S.: Interannual-to-decadal variability of the stratosphere during the 20th century: ensemble simulations with a chemistry-climate model, Atmos. Chem. Phys., 8, 7755-7777, doi:10.5194/acp-87755-2008, 2008.

Gabriel, A. and Schmitz, G.: The Influence of LargeScale Eddy Flux Variability on the Zonal Mean Ozone Distribution, J. Climate, 16, 2615-2627, doi:10.1175/15200442(2003)016;2615:TIOLEF ;2.0.CO;2, 2003.

Garcia, R., Marsh, D., Kinnison, D., Boville, B., and Sassi, F.: Simulation of secular trends in the middle atmosphere, 1950-2003, J. Geophys. Res., 112, D09301, doi:10.1029/2006JD007485, 2007.

Garcia, R. R. and Solomon, S.: A Numerical Model of the Zonally Averaged Dynamical and Chemical Structure of the Middle Atmosphere, J. Geophys. Res., 88, 1379-1400, doi:10.1029/JC088iC02p01379, 1983.

Haynes, P. and Shuckburgh, E.: Effective diffusivity as a diagnostic of atmospheric transport 1. Stratosphere, J. Geophys. Res., 105, 22777-22794, doi:10.1029/2000JD900093, 2000.

Iwasaki, T., Hamada, H., and Miyazaki, K.: Comparisons of Brewer-Dobson Circulations Diagnosed from Reanalyses, J. Meteorol. Soc. Jpn., 87, 997-1006, doi:10.2151/jmsj.87.997, 2009.

Jiang, X., Eichelberger, S., Hartmann, D., Shia, R., and Yung, Y.: Influence of Doubled $\mathrm{CO}_{2}$ on Ozone via Changes in the Brewer-Dobson Circulation, J. Atmos. Sci., 64, 2751-2755, doi:10.1175/JAS3969.1, 2007.

Jiang, X., Pawson, S., Camp, C. D., Nielsen, J. E., Shia, R.-L., Liao, T., Limpasuvan, V., and Yung, Y. L.: Interannual variability and trends of extratropical ozone. Part I: Northern Hemisphere, J. Atmos. Sci., 65, 3013-3029, doi:10.1175/2008JAS2793.1, 2008a.

Jiang, X., Pawson, S., Camp, C. D., Nielsen, J. E., Shia, R.-L., Liao, T., Limpasuvan, V., and Yung, Y. L.: Interannual variability and trends of extratropical ozone. Part II: Southern Hemisphere, J. Atmos. Sci., 65, 3030-3041, doi:10.1175/2008JAS2793.1, 2008b.

Karpetchko, A., Kyrö, E., and Knudsen, B.: Arctic and Antarctic polar vortices 1957-2002 as seen from the ERA-40 reanalyses, J. Geophys. Res., 110, D21 109, doi:10.1029/2005JD006113, 2005.

Lachlan-Cope, T., Connolley, W., and Turner, J.: The role of the non-axisymmetric antarctic orography in forcing the observed pattern of variability of the Antarctic climate, Geophys. Res. Lett., 28, 4111-4114, doi:10.1029/2001GL013465, 2001.

Lamago, D., Dameris, M., Schnadt, C., Eyring, V., and Bruhl, C.: Impact of large solar zenith angles on lower stratospheric dynamical and chemical processes in a coupled chemistry-climate model, Atmos. Chem. Phys., 3, 1981-1990, doi:10.5194/acp-31981-2003, 2003.

Madden, R. and Labitzke, K.: A Free Rossby Wave in the Troposphere and Stratosphere During January 1979, J. Geophys. Res., 86, 1247-1254, doi:10.1029/JC086iC02p01247, 1981.

Manney, G., Froidevaux, L., Santee, M., Livesey, N., Sabutis, J., and Waters, J.: Variability of ozone loss during Arctic winter (1991-2000) estimated from UARS Microwave Limb Sounder measurements, J. Geophys. Res., 108, 4149, doi:10.1029/2002JD002634, 2003. 
Manney, G., Santee, M., Froidevaux, L., Hoppel, K., Livesey, N., and Waters, J.: EOS MLS observations of ozone loss in the 2004-2005 Arctic winter, Geophys. Res. Lett., 33, L04802, doi:10.1029/2005GL024494, 2006.

Miyazaki, K. and Iwasaki, T.: Diagnosis of meridional ozone transport based on mass-weighted isentropic zonal means, J. Atmos. Sci., 62, 1192-1208, doi:10.1175/JAS3394.1, 2005.

Miyazaki, K., Iwasaki, T., Shibata, K., and Deushi, M.: Roles of transport in the seasonal variation of the total ozone amount, J. Geophys. Res., 110, D18309, doi:10.1029/2005JD005900, 2005.

Molina, M. and Rowland, F.: Stratospheric sink for chlorofluoromethanes: chlorine atomc-atalysed destruction of ozone, Nature, 249, 810-812, doi:10.1038/249810a0, 1974.

Monier, E. and Weare, B.: Climatology and trends in the forcing of the stratospheric zonal-mean flow, Atmos. Chem. Phys. Discuss., 11, 11649-11690, doi:10.5194/acpd-11-11649-2011, 2011.

Muller, R., Tilmes, S., Konopka, P., Grooss, J., and Jost, H.: Impact of mixing and chemical change on ozone-tracer relations in the polar vortex, Atmos. Chem. Phys., 5, 3139-3151, doi:10.5194/acp-5-3139-2005, 2005.

Nathan, T. and Cordero, E.: An ozone-modified refractive index for vertically propagating planetary waves, J. Geophys. Res., 112, D02105, doi:10.1029/2006JD007357, 2007.

Newman, P., Schoeberl, M., Plumb, R., and Rosenfield, J.: Mixing rates calculated from potential vorticity, J. Geophys. Res., 93, 5221-5240, doi:10.1029/JD093iD05p05221, 1988.

Oikonomou, E. and O'Neill, A.: Evaluation of ozone and water vapor fields from the ECMWF reanalysis ERA-40 during 1991-1999 in comparison with UARS satellite and MOZAIC aircraft observations, J. Geophys. Res., 111, D14109, doi:10.1029/2004JD005341, 2006.

Oman, L. D., Waugh, D. W., Kawa, S. R., Stolarski, R. S., Douglass, A. R., and Newman, P. A.: Mechanisms and feedback causing changes in upper stratospheric ozone in the 21 st century, J. Geophys. Res., 115, D05303, doi:10.1029/2009JD012397, 2010.

Parish, T., Bromwich, D., and Tzeng, R.: On the role of the Antarctic continent in forcing large-scale circulations in the high southern latitudes, J. Atmos. Sci., 51, 3566-3579, doi:10.1175/15200469(1994)051;3566:OTROTA i2.0.CO;2, 1994.

Randel, W. and Wu, F.: A stratospheric ozone profile data set for 1979-2005: Variability, trends, and comparisons with column ozone data, J. Geophys. Res., 112, D06313, doi:10.1029/2006JD007339, 2007.

Randel, W. J., Udelhofen, P., Fleming, E., Geller, M., Gelman, M., Hamilton, K., D., K., Ortland, D., Pawson, S., Swinbank, R., Wu, F., Baldwin, M. P., Chanin, M. L., Keckhut, P., Labitzke, K., Remsberg, E., Simmons, A. J., and Wu, D.: The SPARC Intercomparison of Middle-Atmosphere Climatologies, J. Climate, 17, 986-1003, doi:10.1175/15200442(2004)017;0986:TSIOMC i2.0.CO;2, 2004.

Randel, W. J., Garcia, R., and Wu, F.: Dynamical Balances and Tropical Stratospheric Upwelling, J. Atmos. Sci., 65, 35843595, doi:10.1175/2008JAS2756.1, 2008.
Renwick, J.: Trends in the Southern Hemisphere polar vortex in NCEP and ECMWF reanalyses, Geophys. Res. Lett., 31, L07209, doi:10.1029/2003GL019302, 2004.

Richard, E., Gerbig, C., Wofsy, S., Romashkin, P., Hurst, D., Ray, E., Moore, F., Elkins, J., Deshler, T., and Toon, G.: Severe chemical ozone loss inside the Arctic Polar Vortex during winter 1999-2000 Inferred from in situ airborne measurements, Geophys. Res. Lett., 28, 2197-2200, doi:10.1029/2001GL012878, 2001.

Rowland, F. and Molina, M.: Chlorofluoromethanes in the Environment, Rev. Geophys., 13, 1-35, doi:10.1029/RG013i001p00001, 1975.

Sabutis, J.: The Short-Term Transport of Zonal Mean Ozone Using a Residual Mean Circulation Calculated from Observations, J. Atmos. Sci., 54, 1094-1106, doi:10.1175/15200469(1997)054;1094:TSTTOZ;2.0.CO;2, 1997.

Sasano, Y., Terao, Y., Tanaka, H., Kanzawa, H., Nakajima, H., Yokota, T., Nakane, H., Hayashida, S., and Saitoh, N.: ILAS observations of chemical ozone loss in the Arctic vortex during early spring 1997, Geophys. Res. Lett., 27, 213-216, doi:10.1029/1999GL010794, 2000.

Singleton, C., Randall, C., Chipperfield, M., Davies, S., Feng, W., Bevilacqua, R., Hoppel, K., Fromm, M., Manney, G., and Harvey, V.: 2002-2003 Arctic ozone loss deduced from POAM III satellite observations and the SLIMCAT chemical transport model, Atmos. Chem. Phys., 5, 597-609, doi:10.5194/acp-5597-2005, 2005.

Singleton, C., Randall, C., Harvey, V., Chipperfield, M., Feng, W., Manney, G., Froidevaux, L., Boone, C., Bernath, P., Walker, K., et al.: Quantifying Arctic ozone loss during the 2004-2005 winter using satellite observations and a chemical transport model, J. Geophys. Res., 112, D07304, doi:10.1029/2006JD007463, 2007.

Stolarski, R. and Cicerone, R.: Stratospheric chlorine: a possible sink for ozone, Can. J. Chem., 52, 1610-1615, doi:10.1139/v74233, 1974.

Trenberth, K.: Storm Tracks in the Southern Hemisphere, J. Atmos. Sci., 48, 2159-2178, doi:10.1175/1520-

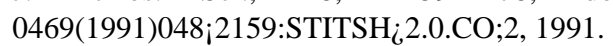

Tung, K.: Nongeostrophic Theory of Zonally Averaged Circulation. Part I: Formulation, J. Atmos. Sci., 43, 2600-2618, doi:10.1175/1520-0469(1986)043;2600:NTOZAC $\dot{i} 2.0 . C O ; 2$, 1986.

Uppala, S. M., Kållberg, P., Simmons, A., Andrae, U., Bechtold, V., Fiorino, M., Gibson, J., Haseler, J., Hernandez, A., Kelly, G., et al.: The ERA-40 re-analysis, Q. J. Roy. Meteorol. Soc., 131, 2961-3012, doi:10.1256/qj.04.176, 2005.

van Noije, T., Eskes, H., van Weele, M., and van Velthoven, P.: Implications of the enhanced Brewer-Dobson circulation in European Centre for Medium-Range Weather Forecasts reanalysis ERA-40 for the stratosphere-troposphere exchange of ozone in global chemistry transport models, J. Geophys. Res., 109, D19308, doi:10.1029/2004JD004586, 2004. 